\title{
Recepção estética de apresentações teatrais com atores com história de sofrimento psíquico*
}

Aline Ernandes Milhomens ${ }^{(a)}$

Elizabeth Maria Freire de Araújo Lima ${ }^{(b)}$

Milhomens $A E$, Lima EMFA. Esthetic reception of theatrical presentations by actors with histories of psychological distress. Interface (Botucatu). 2014; 18(49):377-88.

This study was developed among the audiences of theater groups in which the cast included actors with histories of psychological distress. Its aim was to investigate what is produced at the meeting point between art, madness and society, from studying the esthetic reception of these works. Semi-structured interviews were conducted with members of the audience at three theatrical shows with the intention of understand the relationship between the public and these productions, the meaning assigned to such relationships and their potential for cultural transformation surrounding madness. The interviews were analyzed through the collective subject discourse method. The analysis showed the potential that theater has for weaving a connective "thread" between madness and society, and indicated that the experience of the esthetic reception can make a major contribution towards the work of social and cultural transformation of the imaginary surrounding madness.

Keywords: Mental health. Culture. Esthetics. Art.
Esta pesquisa foi realizada com público de grupos teatrais que possuem, em seu elenco, atores com histórico de sofrimento psíquico, visando investigar, a partir do estudo da recepção estética dessas obras, o que o encontro entre arte, loucura e sociedade produz. Foram realizadas entrevistas semiestruturadas com públicos de três espetáculos teatrais, utilizando-se um roteiro de questões a fim de se compreender a relação estabelecida pelo público com essas produções, o sentido atribuído a elas e seu potencial de transformação cultural em torno da loucura. As entrevistas foram analisadas por meio do método do Discurso do Sujeito Coletivo. A análise evidenciou o potencial do teatro de tecer o "fio" de conexão entre loucura e sociedade e indicou que a recepção estética, ao compor uma experiência, pode ser grande aliada no trabalho de transformação cultural e social do imaginário em torno da loucura.

Palavras-chave: Saúde mental. Cultura. Estética. Arte.

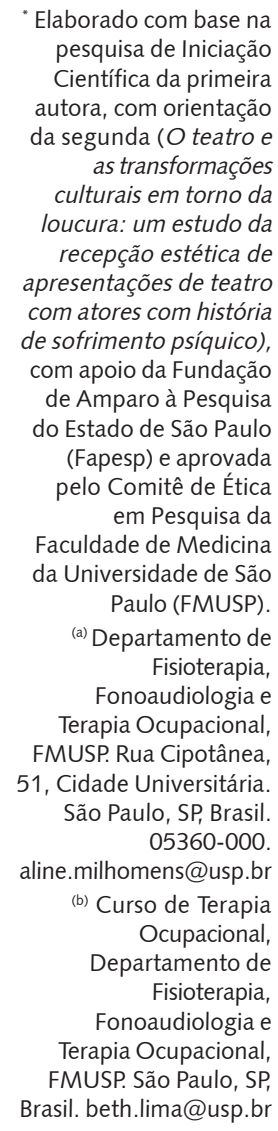

Elaborado com base na pesquisa de Iniciação Científica da primeira autora, com orientação da segunda $(O$ teatro $e$ as transformações culturais em torno da loucura: um estudo da recepção estética de apresentações de teatro com atores com história de sofrimento psíquico) com apoio da Fundação de Amparo à Pesquisa do Estado de São Paulo (Fapesp) e aprovada pelo Comitê de Ética em Pesquisa da Faculdade de Medicina da Universidade de São Paulo (FMUSP).

(a) Departamento de Fisioterapia, Fonoaudiologia e Terapia Ocupacional FMUSP. Rua Cipotânea 51, Cidade Universitária. São Paulo, SP, Brasil 05360-000

aline.milhomens@usp.br

(b) Curso de Terapia Ocupacional, Departamento de Fisioterapia Fonoaudiologia e Terapia Ocupacional, Terapia Ocupacional,
FMUSP. São Paulo, SP Brasil.beth.lima@usp.br 


\section{Introdução}

As mudanças na atenção à saúde mental brasileira, iniciadas pela Reforma Psiquiátrica na década de 1980, proporcionaram a reconfiguração das práticas em saúde mental e a criação de serviços territoriais que oferecem alternativas aos manicômios com ações no campo sociocultural. Centros de Atenção Psicossocial (CAPS), residências terapêuticas, Centros de Convivência e Cooperativa (CECCO), entre outros, foram criados a partir do novo modelo de atenção em saúde mental, referenciado na atenção psicossocial.

Os tratamentos terapêuticos tradicionais foram repensados com vistas à construção de repertórios pautados na produção de vida em articulação com a arte e a cultura.

Essa articulação iniciou-se, nas instituições brasileiras, na primeira metade do século XX, mediante trabalhos desenvolvidos, sobretudo, pelos psiquiatras Osório César em São Paulo e Nise da Silveira, Rio de Janeiro. Estes foram grandes estudiosos das produções plásticas realizadas nos hospitais psiquiátricos que, em associação com artistas plásticos, desenvolveram propostas baseadas na metodologia da livre expressão no trabalho com arte, afirmando e buscando desenvolver o potencial artístico dos pacientes.

O interesse por estas produções e a recepção destas pelo público geraram muitas discussões a respeito do valor artístico das obras e da relação com a arte moderna, desdobrando-se em questionamentos sobre o conceito de arte e de artista ${ }^{1}$. Filósofos, críticos de arte, psiquiatras, psicólogos e artistas passaram a discutir os valores da arte, do fazer artístico, o sentido de expor produções feitas por loucos, assim como os conceitos de recepção e experiência estética, que serão discutidos adiante.

A investigação e a recepção de obras produzidas por pessoas com sofrimento psíquico $^{(c)}$, inseridas em instituições psiquiátricas, remetem ao modo como a loucura é vista e pensada no campo social². Quando apresentadas a um público, este entra em contato com manifestações de pessoas cujo imaginário social as configura como perigosas e marcadas por incapacidades.

O foco na arte e naquilo que se produz na relação público-obra se dá pelo caráter disseminador dessa relação. Discutir, ouvir opiniões e comunicar são fatores essencialmente sociais que compõem e caracterizam o campo artístico e que, em articulação com a saúde mental, podem contribuir para que a pessoa em sofrimento psíquico pertença, atue e seja reconhecida em sua produção, linguagem e papel exercido na sociedade.

A partir dessa discussão, este trabalho foi pensado de modo a propor uma investigação da recepção de obras produzidas no campo das relações entre arte e loucura. O estudo voltou-se para o público de apresentações de teatro com atores com histórico de sofrimento psíquico, que foram ou são usuários de serviços de saúde mental, visando contribuir para a discussão das formas por meio das quais o teatro pode promover transformações culturais e modificar concepções de saúdedoença. Buscou-se, também, fazer emergir algumas categorias que compõem o pensamento coletivo sobre as relações entre teatro e loucura a partir do discurso dos entrevistados.

Desta forma, a pesquisa foi desenvolvida a partir da escuta das expectativas, impressões e opiniões do "público da loucura", nas palavras de João Frayze1. Para o autor, investigar a recepção estética de obras da loucura é uma forma de estudar "a relação de uma cultura com aquilo mesmo que ela exclui"1 (página da citação).

Entendemos, assim, que essa pesquisa pode contribuir para se pensar o potencial dessas obras de atravessar os campos da saúde e da doença, e confrontar (c) Vários termos têm sido utilizados para designar pessoas que passam pela experiência da loucura. Alguns, como psicose ou transtorno mental, apontam para um diagnóstico, indicando o entendimento dessa experiência como doença ou transtorno. Outros, como usuários de serviços de saúde mental, referem-se à inserção e inscrição da pessoa em serviços de atenção. Optamos por utilizar a expressão "sofrimento psíquico" como forma de destacar a experiência subjetiva presente na vida dessas pessoas. 
valores culturais que atribuem desvalor à diversidade, à deficiência, à loucura, à ruptura com as normas ${ }^{3}$.

\section{Referencial teórico}

\section{A recepção das obras da loucura}

Os estudos sobre a relação entre arte e loucura começaram a aparecer no final do século XIX. Já o reconhecimento artístico de formas expressivas produzidas por loucos aparecerá algum tempo depois, em duas importantes publicações. A primeira, publicada em 1921, do psiquiatra Walter Morgenthaler, que causou impacto no meio cultural e artístico europeu por referir-se ao paciente nominalmente e considerá-lo um artista. A segunda, de 1922, intitulada "Expressão da loucura" e de autoria de Hans Prinzhorn, adquiriu destaque por empregar um método de investigação sobre os processos de criação artística por meio de teorias da psicologia. Essas publicações estabeleceram uma nova relação entre arte-loucura ao tratarem, como obras de arte, produções plásticas que dão passagem a expressões da loucura ${ }^{4}$.

No Brasil, essa discussão adquiriu intensidade na Semana de Arte Moderna quando intelectuais, artistas e críticos discutiram sobre o conceito de arte, a relação entre arte e técnica, arte e inconsciente e arte e loucura ${ }^{4,5}$.

Nesta mesma década, o médico psiquiatra, músico e crítico de arte, Osório César, realizou uma análise sistemática dos trabalhos de artes plásticas feitos pelos pacientes internados no Hospital do Juquery. Osório publicou textos sobre essa temática e criou a Escola Livre de Artes Plásticas do Juquery, cujo principal objetivo era o aprendizado da técnica e a formação em arte para os internos. Realizou, também, exposições na tentativa de inserir esses artistas no meio artístico e de apresentar, aos espectadores, o aspecto social e cultural dos alienados ${ }^{6}$.

Nos anos 1940, a psiquiatra Nise da Silveira iniciou outra experiência no Centro Psiquiátrico Nacional, Rio de Janeiro. Em 1947, realizou a primeira exposição, em um espaço de cultura, das produções feitas no ateliê de pintura do setor de Terapêutica Ocupacional do Centro Psiquiátrico. Muitas de suas exposições se seguiram em âmbito nacional e internacional: no MASP, na XVI Bienal de São Paulo, em Paris, Zurique e Roma. Em 1952, Nise inaugurou o Museu de Imagens do Inconsciente, com o objetivo de organizar, conservar e expor as obras.

Essas mostras geraram grande interesse nos meios científicos e culturais, e

(d) Destacamos a querela, publicada em jornais, entre os críticos Mario Pedrosa e Quirino Campofiorito. A este respeito, ver os trabalhos de Dionísio7 e Lima entre outros. dispararam diversas discussões no campo artístico e da saúde mental sobre a temática arte e loucura ${ }^{(d)}$.

\section{Teatro e loucura}

Num contexto de transformação de saberes, valores e cultura, o teatro surge como um dos "fios" de conexão entre a loucura e a sociedade. Grupos amadores e profissionais como Cia. Teatral UEINZZ, Pirei na Cenna, Coral Cênico - Cidadãos Cantantes, e experiências com o Teatro do Oprimido, entre outras, estão em ação nos espaços de arte e nos de serviços de saúde.

Entre os diversos fazeres artísticos, o teatro é uma linguagem de forte expressão, que configura uma possibilidade de interação entre os atores e o público, podendo também contar com a participação direta deste, como se vê no Teatro do Oprimido. 
RECEPÇÃO ESTÉTICA DE APRESENTAÇÕES TEATRAIS ...

Ao assistir uma peça em que alguns atores são pessoas em sofrimento psíquico, o público entra em contato direto com essas pessoas e se confronta com seus próprios preconceitos e imaginário. Dessa forma, o olhar sobre a loucura é lançado dentro de um território artístico, configurando, simultaneamente, uma nova paisagem no campo do sofrimento psíquico e uma nova relação entre os loucos e "aqueles que se dizem sãos". Para Peter Pál Pelbart (p. 65)

O poder de afetação de um acontecimento, para além do deleite que pode propiciar, ou da comoção que produziu e que há de se prolongar, nos força a pensar e a repensar nosso atlas antropológico, obriga-nos a redesenhar nossa geografia mental e certas fronteiras entre saúde e doença, entre a vitalidade e o sofrimento, entre a arte e a inadequação.

Pelbart ${ }^{9}$ diz que este teatro carrega consigo vidas que experimentam limites e tangenciam estados alterados. Essas vidas, sacudidas por tremores causados por rupturas devastadoras e intensidades que transbordam toda forma ou representação, pedem novas formas de linguagem. A criação dessas linguagens questiona a possibilidade expressiva da linguagem hegemônica, gera acontecimentos inverbalizáveis e reinventa o ver e o ouvir.

Hoje, o grande número de produções na interface entre arte-loucura ganhou reconhecimento e ocupou espaço nas políticas públicas de saúde e de cultura. Os Ministérios da Cultura e da Saúde, em um acordo conjunto com a Caixa Econômica Federal, ofereceram, no ano de 2009, um prêmio de incentivo financeiro a projetos culturais realizados por pessoas e grupos em sofrimento psíquico, o prêmio "Loucos pela Diversidade". O programa objetivou construir políticas públicas culturais aos sujeitos em sofrimento psíquico por meio de um estímulo financeiro aos programas que atuam na interface saúde mental e cultura ${ }^{10}$.

Tal ação demonstrou a importância destes trabalhos como uma produção cultural de qualidade que deve ser incentivada. Na fala do secretário da Identidade e Diversidade do Ministério da Cultura, Sérgio Mamberti11, "A experiência estética da criação pode ser usada como umas das mais importantes formas de expressão dessas pessoas, além de contribuir significativamente para a desconstrução de preconceitos".

\section{Experiência e recepção estética}

Neste ponto, faz-se necessário apresentar, inicialmente, a concepção de arte como experiência, proposta pelo filósofo americano John Dewey ${ }^{12}$, noção fundamental para o desenvolvimento desta pesquisa. Segundo Dewey ${ }^{12}$, a experiência faz-se presente continuamente na vida do ser vivo, pois este está em constante interação com as condições ambientais, compondo o próprio processo de viver. Conversas, atitudes e observações despertam pensamentos, sensações e emoções que, quando aprofundados, modificam a experiência de modo a emergir a intenção consciente sobre o que é vivido.

Estas experiências se caracterizam por serem marcantes e não se dissiparem, nem serem facilmente esquecidas. Quando não interrompidas, um fluxo subjetivo contínuo de pensamentos e sensações conduz a pessoa a um estado distinto do estado anterior, passando por uma experiência singular ${ }^{12}$.

Nesta perspectiva, a experiência estética nada mais é que o desenvolvimento intensificado da experiência.

[...] o estético não é algo que se intromete na experiência de fora para dentro, seja pelo fluxo ocioso ou pela idealização transcendental, mas é o desenvolvimento esclarecido e intensificado de traços que pertencem a toda experiência normalmente completa. ${ }^{12}$ (p. 125)

Quando iniciado, esse fluxo se encerrará mediante a consumação da experiência, e não de um cessar, pois, no cessar, a experiência se interrompe, torna-se incompleta, não deixa marcas. Já quando consumida, o fluxo se dá a fim de esgotar o que emerge desse corpo e dessa mente, criando uma nova configuração semiótica que é, também, "produção de território subjetivo a partir das matérias do mundo"13 (p. 188). 
Essa experiência, segundo Dewey, ${ }^{12}$ é decomposta em três fases interdependentes: a fase "prática" indica a interação do corpo com os eventos e objetos que o cercam; a "afetiva" liga todas as partes em um todo único, dando o caráter de totalidade da experiência; e a "intelectual" dá sentido à experiência vivida. Pode-se dizer que, no momento em que essas três dimensões se fazem presentes no campo artístico, a obra é criada, revelando a conexão entre o estético e o artístico, entre a percepção e a criação, compondo a totalidade da experiência da arte ${ }^{14}$.

Em um espetáculo teatral, todo o processo de produção se completa na apresentação do trabalho ao público, aos receptores, de forma que essas três dimensões estão implicadas no processo, produzindo marcas em todos os envolvidos. Este momento configura-se como uma finalização temporal da obra, mas, também, como o início de um processamento e consumação de sentimentos e pensamentos evocados pela apresentação.

Segundo Lima ${ }^{13}$, a experiência estética é essencial para a constituição e apresentação dos sujeitos, pois inaugura a possibilidade de existir frente a um outro. Seguindo a perspectiva da autora, de experiência estética como encontro, quando um sujeito encontra um objeto ou uma pessoa, sensações e pensamentos são movidos, produzindo ressonâncias e despertando o olhar pra si e para o fora. Seja no cotidiano ou numa vivência artística, " as formas mais singulares de expressão são aquelas com maior potência para produzir ressonância"13 (p. 187).

A experiência da loucura, ao encontrar uma expressão singular, tem grande potencial provocador, pois rompe com aquilo que é considerado "normal" e aceito socialmente.

A recepção é um componente indissociável da arte e fundamental para a configuração de uma experiência estética. Segundo Dionísio ${ }^{15}$, a recepção estética é

[...] um processo que não é de todo harmônico, mas envolve conflitos (Didi-Huberman, 2005), e, assim, faz funcionar em nós zonas intermediárias (Winnicot, 1975) de relação que perfazem por meio do olhar a inscrição de subjetividade de cada um, diante de um sem número de associações que fazemos ao ver uma ou outra obra determinada. ${ }^{15}$ (p. 37)

Essas associações, proporcionadas pelo encontro com o objeto (obra, apresentação, o outro etc.), provocam um pensar sobre questões nunca tocadas ou confrontadas que habitam a mente de quem o especta. Segundo Lima ${ }^{13}$, há no objeto estético "uma resolução do problemático que o abre [o espectador] para outras paisagens - caminhos que bifurcam; muros que contém e contornam".

(e) Para Gil ${ }^{17}$, o estudo de campo focaliza uma comunidade que não é necessariamente geográfica, voltada para uma atividade humana específica. A pesquisa é desenvolvida conjugando-se análise documental e bibliográfica com observação direta das atividades dessa comunidade e entrevistas com informantes ${ }^{16}$. A seleção dos informantes, neste caso, se deu por acessibilidade.

\section{Métodos}

Essa pesquisa se caracterizou por ser um estudo de campo de caráter exploratório, ${ }^{16}$ com o objetivo de proporcionar uma aproximação às questões que envolvem a recepção estética de peças de teatro com atores com história de sofrimento psíquico, assunto ainda pouco explorado em pesquisas. Trata-se de um estudo de campo no qual foram solicitadas informações, a uma comunidade que não é geográfica ${ }^{(e)}$ - constituída por espectadores de espetáculos eleitos durante a pesquisa -, acerca da experiência estética vivida por cada um desses durante as apresentações. 
Utilizou-se uma entrevista semiestruturada conduzida a partir de um roteiro composto por sete questões abertas a serem respondidas em duas etapas, antes e depois das apresentações. Na primeira etapa, foram exploradas as motivações, informações prévias e expectativas em relação ao espetáculo. Na segunda, foram abordados os elementos que chamaram atenção, as sensações e interpretações provocadas pelo espetáculo, e a relação entre teatro e saúde mental.

Para a realização das entrevistas, seguiram-se quatro etapas: levantamento de grupos teatrais que possuem, em seu elenco, pessoas que são ou foram usuários de serviços de saúde mental; escolha de uma apresentação para a aplicação de um pré-teste das entrevistas, visando desenvolver os processos de aplicação e adequar o vocabulário empregado ${ }^{17}$; ida a todas as apresentações dos grupos selecionados entre o período de agosto a dezembro de 2011, na cidade de São Paulo, para a realização das entrevistas; por fim, análise das respostas dos entrevistados.

A aplicação do pré-teste ocorreu em um espetáculo da Cia. Teatral Ueinzz ${ }^{(f)} e_{\text {, }}$ posteriormente, para o desenvolvimento da pesquisa, foram realizadas entrevistas semiestruturadas com o público de dois espetáculos do Coral Cênico Cidadãos Cantantes $^{(\mathrm{g})}$ e um da Cia. de Saúde Mental de Teatro ${ }^{\text {(h) }}$, que realizaram apresentações no período da pesquisa. Optou-se em incluir o Coral Cênico, pois apesar de ser um coral cuja linguagem artística é a música, as linguagens do teatro e da performance fazem-se presentes na construção do trabalho deste grupo.

Para encontrar as pessoas que seriam entrevistadas, informantes potenciais para esta pesquisa, mapearam-se os grupos de teatro na cidade de São Paulo e, mediante contato, solicitaram-se informações a respeito da agenda de apresentações no período da pesquisa. Para encontrar os grupos, fez-se uma pesquisa por diversos meios: internet, sites de busca, utilizando, como palavras-chave, "teatro" e "saúde mental"; telefone, contatando todos os CAPS da cidade de São Paulo; agendas culturais on-line; redes sociais; guia cultural de jornais de grande circulação do Estado de São Paulo; por fim, contatando pessoas conhecidas que trabalham na interface arte e clínica.

A partir desse levantamento, localizamos três espetáculos com apresentações agendadas para o período de realização da pesquisa. Um espetáculo da Cia de Saúde Mental de Teatro, com apresentação da peça "O Alienista" de Machado de Assis, no gênero comédia, e duas apresentações do mesmo espetáculo do Coral Cênico Cidadãos Cantantes, construído em torno do tema "A Cidade de São Paulo".

O contato com os entrevistados era feito antes da apresentação. Uma vez expresso formalmente o interesse em participar do estudo e autorizada a utilização dos dados para a pesquisa através da assinatura do TCLE - Termo de

Consentimento Livre e Esclarecido -, dava-se início à aplicação da primeira parte do roteiro de questões. Explicava-se a divisão do roteiro em duas etapas, sendo que a primeira seria respondida a próprio punho antes da apresentação, e a segunda após. O roteiro ficava em posse dos entrevistados, orientados a entregarem, ao pesquisador, ao final da apresentação, após responderem a segunda etapa.

Na primeira apresentação em que os questionários foram aplicados, foi dada, aos entrevistados, a possibilidade de responderem as perguntas da segunda etapa via e-mail, julgando ser interessante respondê-las após um tempo da apresentação. Porém, grande parte dos que optaram por esta abordagem não responderam ao email, trazendo prejuízo para a pesquisa e para a composição dos discursos da segunda etapa. Após esta experiência, nas apresentações subsequentes, não foi dada a opção de resposta via e-mail. Desta forma, foi possível atingir um total de 21 entrevistados nos espetáculos levantados para a pesquisa.

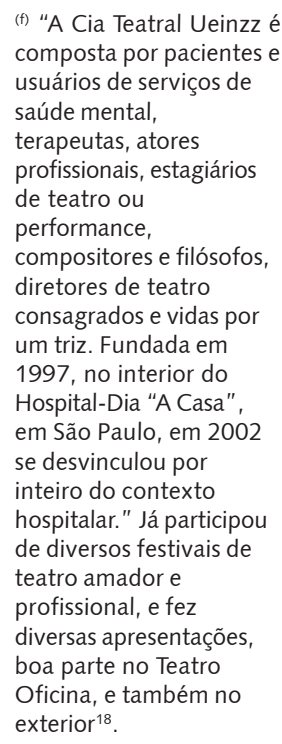

(f) "A Cia Teatral Ueinzz é composta por pacientes e usuários de serviços de saúde mental, terapeutas, atores profissionais, estagiários de teatro ou performance, compositores e filósofos, diretores de teatro consagrados e vidas por um triz. Fundada em 1997, no interior do Hospital-Dia "A Casa", em São Paulo, em 2002 se desvinculou por inteiro do contexto hospitalar." Já participou de diversos festivais de teatro amador $\mathrm{e}$ profissional, e fez diversas apresentações, boa parte no Teatro Oficina, e também no exterior ${ }^{18}$.

(g) O Coral Cênico Cidadãos Cantantes é um projeto de prática musical em grupo que sustenta uma experimentação entre canto coral, artes e saúde. Sua composição é heterogênea, reunindo usuários de serviços de saúde mental, pessoas em situação de vulnerabilidade social e pessoas da população em geral, interessadas nesta construção artística $^{19}$.

(h) A Cia Saúde Mental de Teatro é um grupo formado por pacientes da rede pública da saúde mental de Suzano - SP e profissionais da área da saúde mental e das artes cênicas. Teve início em abril de 2008 com uma oficina. Hoje, a Cia é composta por grupos de três oficinas com mais de trinta pacientes, com diversas apresentações na região de São Paulo ${ }^{20}$. 
A análise de dados buscou compreender: as concepções presentes no público em relação ao encontro entre loucura, teatro e produção artística e cultural; como se deu a relação do público com as apresentações teatrais; e investigar se as afetações produzidas pelos espetáculos provocaram modificações nas concepções sobre loucura.

Como técnica de pesquisa empírica, utilizou-se o método do Discurso do Sujeito Coletivo (DSC), formulado e desenvolvido por Fernando Lefèvre, como um auxílio no tratamento dos dados presentes nas entrevistas. O DSC consiste em reunir, sob a forma de discursos únicos redigidos na primeira pessoa do singular, conteúdos de diversos depoimentos com sentidos semelhantes ${ }^{21}$.

Para apresentação dos dados, seguem as questões ordenadas conforme o roteiro utilizado e as respectivas categorias compostas a partir da técnica do DSC.

\section{Resultados}

\section{Questão 1:}

\section{Como soube da apresentação? O que te motivou a assistir ao espetáculo?}

Em relação ao modo como o sujeito entrou em contato com a apresentação do espetáculo, foi possível compor três categorias de respostas: conhecimento do grupo ou de integrantes do grupo; convite de amigos e familiares; e programação cultural do evento/cidade/escola. Ao analisá-las, pôde-se observar que a primeira e a segunda categorias representaram grande parte do público, já que um grande número de sujeitos referiu ter vindo assistir ao espetáculo por conhecer o grupo ou algum integrante (50\%), ou por convite de parente ou amigo (33\%). Apenas $17 \%$ do público referiram ter adquirido conhecimento da apresentação pela programação cultural da cidade ou do evento que estava acompanhando. Quanto às motivações para assistir ao espetáculo, 70\% dos sujeitos foram movidos pelo interesse pelas artes e 30\% afirmaram interesse nas questões de saúde mental.

Percebe-se assim que, embora a divulgação dessas apresentações se dê, sacima de tudo, no "boca a boca" do que por divulgação em órgãos da mídia, o interesse por elas pauta-se majoritariamente em um interesse por produções artísticas e culturais.

\section{Questão 2:}

\section{Possui alguma informação breve sobre o espetáculo?}

Dois terços dos entrevistados responderam não possuir nenhuma informação sobre o espetáculo, e somente alguns relataram breve conhecimento sobre o grupo ou sobre a apresentação. Com esta pergunta, buscou-se verificar se o público tinha informação relativa à participação no elenco de pessoas com a experiência do sofrimento psíquico. Somente uma pessoa relatou saber que o grupo era "formado por atores que sofrem de alguma faculdade mental". Isso é interessante, pois, embora, como visto na primeira questão, grande parte do público conheça alguém que faz parte do grupo, a maioria não relatou ter informações sobre o trabalho realizado. Talvez os entrevistados tivessem alguma informação, mas não a consideraram relevante a ponto de mencioná-la em suas respostas.

\section{Questão 3:}

\section{Quais são as suas expectativas em relação ao espetáculo?}

A maioria das pessoas $(80 \%$ ) relatou ter boas expectativas, assim como um despertar de sentimentos e aquisição de aprendizado:

"Minhas expectativas são as melhores possíveis. Espero que seja bem bonito, legal, divertido, agradável, que traga muita emoção e me faça sentir prazer. Ouvi vários elogios sobre o grupo e assim espero ver coisas novas, diferentes do cotidiano, coisas para mudar e acrescentar. Compreender a mensagem que será passada e poder aprender com esses atores". 
RECEPÇÃO ESTÉTICA DE APRESENTAÇÕES TEATRAIS ...

Apenas $20 \%$ dos entrevistados relataram ter como expectativa uma maior aproximação com a deficiência e/ou sofrimento psíquico:

"Quero quebrar um pouco mais o conceito de paciente psiquiátrico em mim, conhecer os trabalhos de inclusão social e os potenciais que existem nas pessoas para ajudar a mostrar para a sociedade que eles são "normais". Saber que tipo de deficiências os componentes do grupo tem ou vão expor durante o espetáculo".

\title{
Questão 4:
}

\section{Quais elementos te chamaram atenção no espetáculo?}

Para essa questão, três categorias foram compostas: características estéticas do espetáculo; afetos e relação grupal; e diversidade dos integrantes. Dentre as três, a que teve mais destaque entre o público $(60 \%)$ foi a "características estéticas do espetáculo":

\begin{abstract}
"A diversidade de cores, de pessoas, de vozes, o figurino, a performance, o movimento desordenado, a expressão cultural, a expressão facial, a interação com o público, a organização, os esforços dos atores em interpretar o texto, o texto na ponta da língua, a interpretação cênica e interação com a platéia".
\end{abstract}

Percebe-se, neste discurso, que a qualidade estética do espetáculo é o que mais chama atenção. Este dado aponta para a potência de experiência estética e cultural dos espetáculos e seu deslocamento do campo das práticas em saúde. Em um espetáculo com atores com sofrimento psíquico, o que se sobressai são os elementos artísticos, não a loucura ou a problemática de seus integrantes.

A segunda categoria "afetos e relação grupal" esteve presente em 30\% dos discursos, como será visto e aprofundado na discussão da questão 5.

\section{Questão 5:}

\section{Cite algumas sensações e/ou interpretações provocadas pelo espetáculo}

Boas sensações e sentimentos; interação grupo-público; e viver e enfrentar a vida, foram as três categorias decompostas das respostas dos entrevistados. A primeira delas representou $85 \%$ das falas dos entrevistados, já as outras compuseram, respectivamente, 10 e 5\% dos discursos coletados.

Chamou atenção, nos discursos da primeira categoria, a frequência das palavras alegria, felicidade e sorriso, presente em $66 \%$ das expressões-chave. Esta alegria referida por grande parte do público pode ter se dado pelo gênero dos trabalhos, uma vez que a Cia. de Saúde Mental apresentou uma comédia e o Coral Cênico apresentou músicas sobre a cidade de São Paulo, que convidavam o público a cantar junto. Entretanto, há outros fatores que se relacionam a esta sensação compartilhada pelo público. Pode-se relacioná-las às vivências de interação grupos-público, de vitalidade e de enfrentamento de dificuldades da vida. Neste sentido, parece importante observar que a alegria pode estar relacionada a uma potência política e clínica dos espetáculos, produzindo aumento da realidade compartilhada e da força de agir e de pensar nos atores e no público a um só tempo. Isto porque a alegria é considerada, aqui, uma potência política e subjetivante ${ }^{22}$.

\footnotetext{
"Muitas sensações! Sensações muito boas, de inclusão. Difícil descrever... nostalgia, alegria, vontade de sorrir, admiração, bem-estar, felicidade, carisma, relaxamento, entusiasmo, tranquilidade, expressos com liberdade. Me emocionei quando o elenco se reuniu no palco, todos interagiram, cada um do seu jeito, adorei, amei!".
}

Se considerarmos a ideia de Dewey ${ }^{12}$ de que uma obra será verdadeiramente artística quando ocorrer uma recepção prazerosa aos olhos de quem cria e aos olhos de quem recebe, todos os espetáculos considerados para a pesquisa teriam qualidades de experiência estética. Não somente por um poder de 
afetação e de despertar emoções como o DSC da questão 5 expressa, mas, também, no aspecto dos elementos estéticos fortemente trazido na questão 4.

Outra sensação presente em alguns dos sujeitos entrevistados foi a vontade de participar e se integrar ao espetáculo. Para estes, a recepção estética pareceu ser tão intensa que muitos quiseram fazer parte, compor aquilo que espectavam:

"A interação do grupo com o público deixou o clima mais simpático e alegre. Fiquei com vontade de participar do espetáculo. Sensação de se sentir diferente, único, mas ao mesmo tempo integrante do grupo".

Pouco menos frequente, mas de importância para a análise por relacionar-se à ideia de experiência estética enquanto transformação, foi o sentimento de querer viver e enfrentar a vida com mais intensidade:

\footnotetext{
"Reconhecer os limites e ter a disposição para enfrentar. Vontade de viver a vida com mais intensidade, pois as pessoas que tem problema de saúde mental estavam lá firmes e fortes enquanto nós às vezes ficamos reclamando da vida".
}

Essas três categorias, que emergiram das respostas a esta pergunta, podem ser relacionadas com as três fases que compõem, segundo Dewey ${ }^{12}$, a experiência estética: a fase prática, a intelectual e a afetiva. É possível pensar que cada sujeito entrevistado trouxe, em sua resposta, aspectos compartilhados da experiência de modo singular, tal como vividos em seu corpo. A fase "prática", que é a interação do corpo com o objeto, no caso, o espetáculo, é demonstrada nos discursos dos sujeitos que expressaram uma vontade de querer compor o grupo e participar da apresentação. A "intelectual", segundo o autor, é a fase que dá sentido à experiência vivida no encontro com o objeto - estaria forte nos sujeitos que relataram um sentimento de querer viver e enfrentar a vida com mais intensidade. Por fim, a fase afetiva, expressa nas sensações de alegria, leveza, bem-estar etc., demonstrada no primeiro DSC desta questão. Essa fase é a responsável por ligar todas as partes em um único todo e dar o caráter de totalidade à experiência.

Assim, é possível afirmar que o processo de produção e consumação de sentimentos e pensamentos evocados pela apresentação foi iniciado e a recepção foi concretizada. O espetáculo configura-se somente como finalização temporal da obra e início de um processamento desses despertares; a afetação na vida da pessoa somente poderá ser significada por ela no decurso do tempo por vir.

\section{Questão 6:}

\section{Em relação às expectativas, algo te surpreendeu?}

Essa questão foi a única sobre a qual se formou somente uma categoria de resposta: surpresa pela qualidade do espetáculo e potencialidade dos atores.

"SURPREENDENTE!!! O espetáculo inteiro foi fantástico, foi muito bom, se saíram muito bem. Todos estavam envolvidos e preparados, não esperava tanta qualidade na peça. Achei interessante a parte das artes cênicas, me surpreendi pela desenvoltura do grupo, o modo como eles interpretaram, o talento expressivo de alguns participantes, a forma única deles se comportarem no palco, a sincronia, gente que sabe atuar. Por mais que saibamos o contexto do espetáculo e dos atores, criamos um pré-conceito sobre tudo, assistindo a peça esqueci desses "detalhes", estava ali entregue ao espetáculo. Nunca imaginei que pessoas tão especiais conseguissem passar para nós emoções assim tão sinceras. As expectativas foram ultrapassadas e as diferenças são deixadas de lado".

Percebeu-se, assim, que essas formas singulares de expressão tiveram a potência de produzir ressonância nos espectadores ${ }^{13}$. O público dos espetáculos pesquisados foi provocado no sentido de se 
RECEPÇÃO ESTÉTICA DE APRESENTAÇÕES TEATRAIS ...

desprender de pré-conceitos e romper com aquilo que é considerado "normal" e aceito socialmente. É importante, ainda, destacar que, se o público ficou tão surpreendido com a qualidade dos espetáculos e com as potencialidades dos atores, isto indica um imaginário anterior de que os trabalhos não teriam estas qualidades. Neste sentido, as apresentações cumprem um papel de transformação cultural em torno da loucura.

Questão 7:

Para você, qual a relação entre teatro e saúde mental?

Nesta última pergunta, objetivou-se sair do foco do espetáculo em questão para se aproximar da ideia dos entrevistados sobre a relação entre teatro e saúde mental. Três categorias delinearam a opinião do público entrevistado: teatro como uma forma de promoção de saúde e bem-estar; teatro como uma forma de expressão; e teatro como uma forma de inclusão. Dessas categorias, a primeira representou $50 \%$ dos entrevistados e a segunda $30 \%$. Pode-se perceber que se assemelham por caracterizarem o teatro como um "canal", uma saída para o sofrimento ou "liberação das emoções". Isso demonstra que o público reconhece e valoriza (ao fazer a relação com a saúde e o bem-estar) a importância de outras formas de expressão como parte da vida de uma pessoa e, sobretudo, de pessoas com a experiência do sofrimento psíquico que sofreram e/ou sofrem rupturas e momentos intensos de transbordamento das emoções. Esta relação feita pelo público pode ser relacionada ao pensamento de Augusto Boal de que as artes cênicas não são somente um meio de libertação das prisões psíquicas e físicas, mas, também, um meio de liberação das prisões sociais ${ }^{23}$. Este último aspecto aparece na terceira categoria: teatro como uma forma de inclusão.

"Acredito que o teatro faça com que essas pessoas sejam mais respeitadas, sem sofrerem preconceitos. Numa peça, você não consegue saber quem é a pessoa com deficiência, pois elas trabalham perfeitamente bem como qualquer outra. Qualquer deficiência não impede que as pessoas mostrem suas capacidades, e o teatro abre esse espaço".

\section{Discussão e conclusões}

A análise das entrevistas evidenciou o poder de afetação que um espetáculo com atores com a experiência do sofrimento psíquico pode ter sobre seu público, assim como a potência desses espetáculos de se deslocarem do campo das práticas em saúde para o campo das práticas artísticas e culturais.

É importante apontar que, durante os seis meses de desenvolvimento da pesquisa de campo, foi possível entrevistar o público de apenas três espetáculos teatrais. O reduzido número de espetáculos que ocorreram durante esse período leva a um interesse em aprofundá-la, podendo investigar a experiência de públicos de outros espetáculos e apresentações de outros grupos.

Além disso, percebeu-se que a divulgação desses espetáculos ainda está muito restrita a uma divulgação "boca a boca" de amigos e familiares, evidenciando uma dificuldade de serem incluídos em programações culturais de jornais e revistas de grande circulação. Isso talvez demonstre, ainda, um nãoreconhecimento desses grupos na categoria de arte pelas mídias de divulgação.

Em relação à recepção estética, pôde-se visualizar quanto os entrevistados foram atingidos por diversas sensações e pensamentos e quanto estes os mobilizaram subjetivamente sobre um novo olhar da loucura. A partir do momento que o público entrevistado mostrou-se surpreendido pelo espetáculo, é possível afirmar que essa surpresa os fez redesenhar a geografia mental e certas fronteiras entre saúde e doença, entre a vitalidade e o sofrimento, entre a arte e a inadequação ${ }^{8}$.

Essa pesquisa mostrou que o teatro tem o potencial de tecer o "fio" de conexão entre a loucura e sociedade pelas qualidades artísticas, pelos elementos estéticos e afetivos, e pelo caráter admirável. O teatro, incluindo-se atores e espectadores como compositores deste, é um espaço de criação e reprodução de modos de ser e de existir. 
Os estudos da experiência e da recepção estética produzem uma nova forma de pensar o toque dos olhos sobre uma produção. Produção esta, artística ou não, que ressoa no corpo e na mente de todos que se disponibilizam ao encontro e se deixam levar pelo fluxo das sensações e emoções que despertam e agem sobre si.

A arte, como uma das disparadoras dessa instigação interna, afirma seu poder de afetação sob os sujeitos durante todo seu processo de produção. A pessoa que a produz, a percebe, e a pessoa que a percebe, a reproduz dentro de si. Esse "entremeio" da afetação é o que dá início à experiência.

Diante do material levantado e dos aspectos apresentados, pode-se apontar que a recepção estética, ao compor uma experiência, apresenta-se como grande aliada no trabalho de transformação do imaginário sobre a loucura, trazendo-a, também, para o lugar do vivível, do contato, do toque, do encontro e da experiência.

\section{Colaboradores}

Após a conclusão da pesquisa, as duas autoras trabalharam em conjunto para a elaboração deste artigo.

\section{Referências}

1. Frayze-Pereira JA. Olho d'água: arte e loucura em exposição. São Paulo: Escuta; 1995.

2. Lima EMFA. A produção e a recepção dos escritos de Qorpo-Santo: apontando transformações nas relações entre arte e loucura. Interface (Botucatu). 2010; 14(33):437-47.

3. Nicácio MF. O processo de transformação da saúde mental em Santos: Desconstrução de saberes, instituições e cultura [tese]. São Paulo (SP): Pontifícia Universidade Católica de São Paulo; 1994.

4. Ferraz MHCT. Arte e loucura: limites do imprevisível. São Paulo: Lemos Editorial; 1998.

5. Lima EMFA. Arte, clínica e loucura: território em mutação. São Paulo: Summus, Fapesp; 2009.

6. Lima EMFA. Oficinas, laboratórios, ateliês, grupos de atividades: dispositivos para uma clínica atravessada pela criação. In: Costa CM, Figueiredo AC, organizadores. Oficinas terapêuticas em saúde mental - sujeito, produção e cidadania. Rio de Janeiro: Contra Capa Livraria; 2004. p. 59-81.

7. Dionísio $\mathrm{GH}$. Museu de imagens do inconsciente: considerações sobre sua história. Psicol Cienc Prof. 2001; 21(3):30-5.

8. Pelbart PP. Teatro nômade. Rev Ter Ocup Univ São Paulo. 1998; 9(2):62-9.

9. Pelbart PP. Ueinzz - viagem a Babel. In: Pelbart PP, organizador. A vertigem por um fio. São Paulo: Iluminuras; 2000. p. 99-108.

10. Ministério da Cultura. Loucos pela diversidade [Internet]. 2009 [acesso $2011 \mathrm{Fev}$ 20]. Disponível em: http://www.cultura.gov.br/site/2009/11/20/loucos-peladiversidade-7/

11. Ministério da Cultura. Loucos pela diversidade [Internet]. 2007 [acesso $2011 \mathrm{Fev}$ 20]. Disponível em: http://www.cultura.gov.br/site/2007/08/17/loucos-peladiversidade/ 
RECEPÇÃO ESTÉTICA DE APRESENTAÇÕES TEATRAIS ...

12. Dewey J. A arte como experiência. São Paulo: Martins; 2010.

13. Lima EMFA. Objetos-cicatriz e recepção estética: experimentando pensamentos em meio a obras em obra. Cad Subj. 2011; 8:187-93.

14. Kastrup V. Experiência estética para uma aprendizagem inventiva: notas sobre a acessibilidade de pessoas cegas a museus. Inform Educ. 2010; 13(2):38-45.

15. Dionísio GH. Recepção estética: intermédios de experiência perceptiva. In: Castro ED, Ferro LF, Barbosa ND, Isoda NMT, Okuyama PM, organizadores. Programa Permanente Composições Artísticas e Terapia Ocupacional - PACTO. São Paulo: Curso de Terapia Ocupacional da FMUSP; 2007. p. 36-40. Catálogo virtual; ilustrado.

16. Gil AC. Métodos e técnicas de pesquisa social. 5a ed. São Paulo: Atlas; 1999.

17. Gil AC. Como elaborar projetos de pesquisa. 3a ed. São Paulo: Atlas; 2002.

18. Cia. Teatral Ueinzz. Site do Núcleo de Subjetividades [Internet]. s/d [acesso 2013 Nov 10]. Disponível em: http://www.pucsp.br/nucleodesubjetividade/ueinzz.htm

19. Maluf JCG, Lopes IC, Bichara TAC, Silva JA, Valent IU, Buelau RM, et al. O Coral Cênico Cidadãos Cantantes: um espaço de encontro entre a música e a saúde. Rev Ter Ocup USP. 2009; 20(3):199-204.

20. Cia. Saúde Mental de Teatro [Internet]. Suzano (SP); s/d [acesso 2013 Nov 1]. Disponível em: http://ciasaudementaldeteatro.blogspot.com.br/p/quem-somos.html

21. Lefevre F, Levefre AMC, Marques MCC. Discurso do Sujeito Coletivo, complexidade e auto-organização. Cienc Saude Colet. 2009; 14(4):1193-204.

22. Chauí M. Desejo, paixão e ação na ética de Espinosa. São Paulo: Cia. das Letras; 2011.

23. Campos FN. Contribuições das Oficinas Terapêuticas de Teatro na Reabilitação Psicossocial de Usuários de um CAPS de Uberlândia-MG [dissertação]. Uberlândia (MG): Universidade Federal de Uberlândia; 2004.

Milhomens AE, Lima EMFA. Recepción estética de presentaciones teatrales con actores con historia de sufrimiento psíquico. Interface (Botucatu). 2014; 18(49):377-88.

Esta encuesta se realizó con el público de grupos teatrales que tienen en su reparto a actores con historial de sufrimiento psíquico, con el objetivo de investigar a partir del estudio de la recepción estética de esas obras lo que produce el encuentro entre arte, locura y sociedad. Se realizaron entrevistas semiestructuradas con públicos de tres espectáculos teatrales para comprender la relación establecida por el público con esas producciones, el sentido atribuido a ellas y su potencial de transformación cultural alrededor de la locura. Las entrevistas se analizaron con el método del discurso del sujeto colectivo. El análisis dejó en evidencia el potencial del teatro para tejer el "hilo" de la conexión entre locura y sociedad e indicó que la recepción estética puede ser una gran aliada en el trabajo de transformación cultural y social del imaginario alrededor de la locura.

Palabras clave: Salud mental. Cultura. Estética. Arte.

Recebido em 02/12/13. Aprovado em 23/01/14. 